\title{
Primary Peritoneal Undifferentiated Carcinoma
}

National Cancer Institute

\section{Source}

National Cancer Institute. Primary Peritoneal Undifferentiated Carcinoma. NCI

Thesaurus. Code C162562.

An extremely rare carcinoma arising from the peritoneum. It is characterized by the presence of a diffuse malignant infiltrate that is composed of epithelial cells without evidence of glandular or squamous differentiation. 